\title{
Importance of SEM in the Study of Fractography, Camshaft Failure
}

\author{
González-Mancera G. ${ }^{1}$ and González-González D. E. ${ }^{1}$ \\ ${ }^{1 .}$ Universidad Nacional Autónoma de México, Facultad de Química. Departamento de Ing. Metalúrgica, \\ Ciudad Universitaria, D. F. México.
}

A camshaft is an important automotive part that automates car engine combustion. Most camshafts are made of cast irons to achieve large volume productions and others using CNC machining of steel to achieve a high-quality product but low volume production. In material science and engineering, fractography is one of the most relevant methods used in failure analysis and fracture mechanics. This technique is used to determine the cause of failure by examining the fracture surface. The fracture surfaces can be classified as ductile or brittle depending on the characteristics. In Ductile fracture present mostly, plastic deformation in the surroundings and a bright granular o fibrous surface. In the other hand, brittle fracture presents large crack propagation without plastic deformation and an opaque irregular surface.

The current work examines the fracture of a camshaft using fractography. The sample was cleaned with water-based, organic solvent and acetic acid in ultrasonic baths to eliminate possible contamination and atmospheric oxidation. After the sample was analyzed by Scanning Electron Microscopy (SEM) observation, it shown this material is a nodular cast iron. At low magnification the characteristic fracture pattern indicates a torsion stress failure $[1,2]$. It was observed v-shaped cracks known as Chevron marks and they converge in the fracture initial zone. The initial crack grows due to stress concentration known as fatigue. Those marks are parallel to each other and perpendicular to the propagation direction (Figure 1a), called beach or clamshell marks. Also, there were Ratchet and River marks in the fracture surface and inside respectively, showing a fast-growing crack propagation (Figure 1a). The fracture surface was a combination of initial crack zones surrounded by a fatigue propagation area and a final ductile zone with plastic deformation (Figure 1b). There was no evidence of creep deformation or corrosion. The fracture initial zone was brittle involving cleavage looking cracks, indicating transgranular fractures with bright flat surfaces (Figure 1c). The fatigue zone presented small parallel marks called striations that are a clear evidence of trans granular fatigue propagation (Figure 1d). In conclusion the cast iron material is fragile due nodular structure of carbon, it presents brittleness and rapid fatigue crack propagation, besides nodular carbon generates river marks that speed up the material failure.

\section{References:}

[1] Nunez, R. M., \& Bagnoli, D. L, ASM International (1987), p. 200.

[2] Ortegui, J. L., "Failure Analysis”, (Springer, New York) p. 19. 

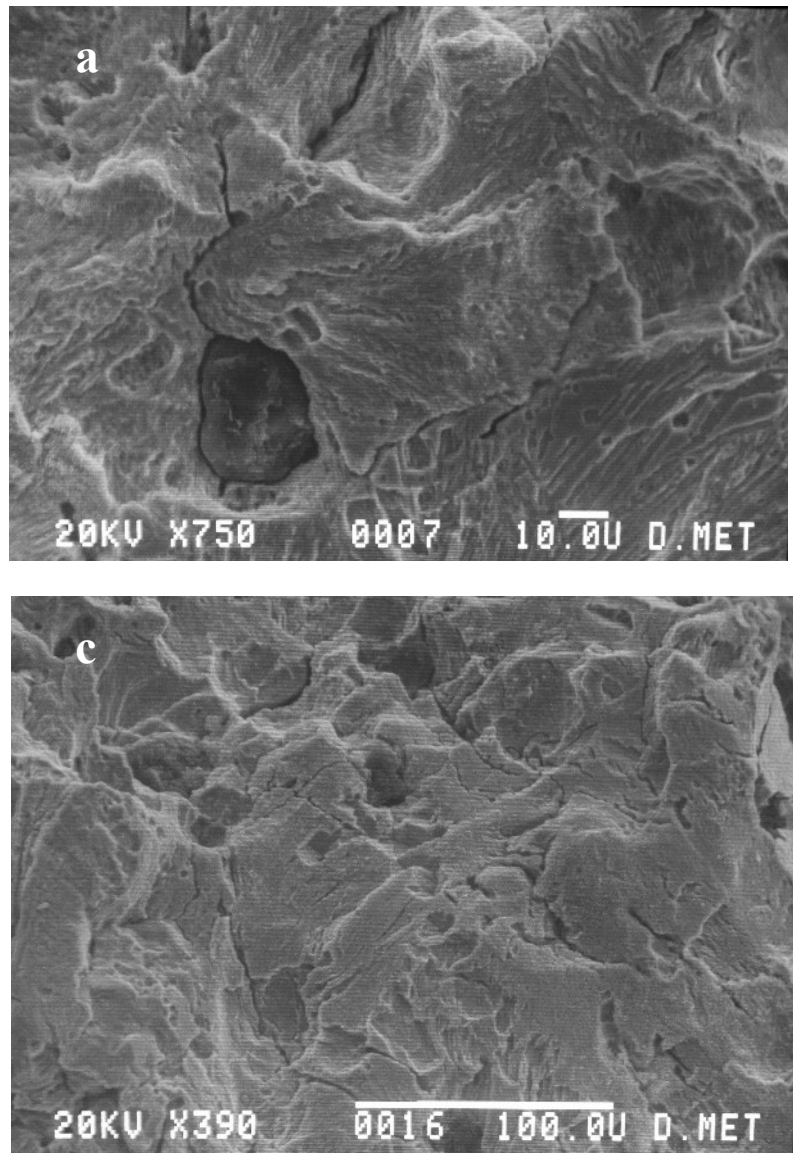
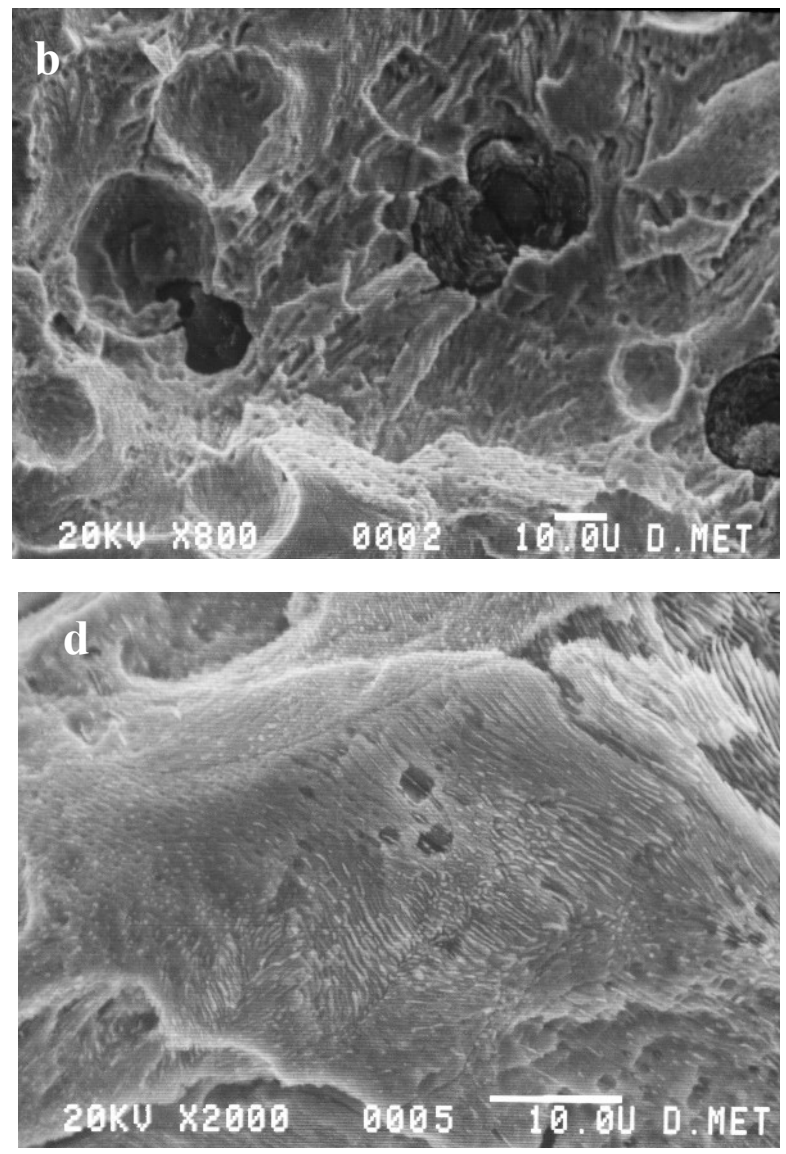

Figure 1. Micrographs of SEM of Camshaft failure. (a) It shows crack propagation from nodular carbon. (b) It reveals fatigue propagation in a ductile zone. (c) It presents the brightness zone where origin the fracture. (d) It shows the striation characteristic of transgranular fracture. 